\title{
Jesús Reyes Heroles, hombre de acción, hombre de historia
}

\begin{abstract}
Probablemente el medio en que vivo y actúo me induzca a creer que México no tiene en su historia un lastre por abuso, ni le aqueja la amnesia por desuso.
\end{abstract}

$\mathrm{P}$ ara comprender al ideólogo, al político, al historiador Jesús Reyes Heroles, hay que trazar sendas paralelas entre su desarrollo biográfico ${ }^{1}$ y la historia contemporánea de México, de la cual, sin duda, fue protagonista significativo. Si, como él preconizara, todos los caminos conducen a la historia y la historia está en la entraña de todo conocer o hacer, el motivo de su proceder estuvo intimamente ligado con el compromiso y su función pública en el ámbito de la vida nacional.

Nacido al iniciarse apenas el proceso de reconstrucción, el 3 de abril de 1921, su generación estaría delimitada por quienes participaron de una visión esencialmente conservadora que se pronunció por consolidar e institucionalizar una intención politica -estrecha y constrictiva - que rechazaba la violencia y el radicalismo: y los hombres del medio siglo, herederos a trasmano de la Revolución. que con irreverencia se atrevian a cuestionarla y a buscar, con un propósito mucho más amplio, los nuevos rumbos, que coadyuvasen a la transformación del país.

El principio

El origen español del padre, Jesús Reyes, y la desahogada situación económica de la familia de su madre, Juana Heroles, arraigada en Tuxpan, Veracruz, marcaron el destino de quien habria de llegar a múltiples cargos políticos e instancias culturales, menos a la de la Presidencia, limitado como estuvo siempre por el precepto constitucional que impedia aspirar al cargo a quienes no fuesen hijos de padres mexicanos. ${ }^{2}$

1 Cf. Laura Solares Robles, Agustin Sánchez González, "Bibliohemerografia" y "Semblanza biográfica", Jesús Reyes Heroles. Vida y obra, México. Asociación de Estudios Históricos y Políticos Jesús Reyes Heroles, A.C., 1991 (Cuadernos 1).

${ }^{2}$ La Constitución Política de los Estados Unidos Mexicanos, en su capitulo III, artículo 
Fue la suya una infancia compleja, algo que podria atribuirse en parte a los cambios de residencia familiar: Tampico, Ciudad Victoria y San Luis Potosí -donde en el Instituto Científico y Literario Autónomo cursó la preparatoria- ${ }^{3}$ para arribar a la ciudad de México, en el ocaso del cardenismo, como alumno en la Facultad de Derecho de la Universidad Nacional Autónoma de México, de la que en 1944 obtuvo el título de abogado con la tesis Tendencias actuales del Estado. ${ }^{4}$

Recién llegado a la capital del país. Reyes Heroles se involucró en el mundo de la política y de los políticos: fue ayudante del general Heriberto Jara, a la sazón presidente del Partido de la Revolución Mexicana. Desde entonces no habria deslindes ni brechas entre su vida como historiador, investigador, ideólogo, escritor, orador y profesor, y su pasión por la política, por el hacer, el conservar, valiéndose para ello del cambio,

[...] una sociedad que vive en desarrollo nunca se detiene, siempre está en movimiento, cambiando. $\mathrm{Y}$ el cambio se racionaliza y se planea buscándolo, o se improvisa e impone. Los cambios, las modificaciones en la sociedad, son tan dinámicos, son tan rápidos, que a veces dejan rezagados a aquellos que se dedican a su análisis y su estudio [...] Tan importante es la meta, el destino, como la ruta, el camino [...] jCambiemos todo lo que debamos cambiar: mantengamos todo lo que debemos mantener! Una sociedad sólo se conserva en la medida en que puede cambiar, pero, a la vez sólo cambia en la medida en que puede conservar. Quienes no conservan algo del pasado, dificilmente construyen algo para el futuro. ${ }^{5}$

82 establece: "Para ser Presidente se requiere: I. Ser ciudadano mexicano por nacimiento. en pleno goce de sus derechos, e hijo de padres mexicanos por nacimiento". El 2 de septiembre de 1993. dicho articulo fue reformado permitiendo asi que los hijos de padres extranjeros puedan aspirar a ser presidentes, modificación que entrará en vigor hasta el año 2000.

${ }^{3}$ De esa época precisamente es el primer texto publicado de Jesús Reyes Heroles: "Humanismo y Revolución", Labor, Revista mensual de Cultura, núm. 2, San Luis Potosí. octubre de 1939, pp. 19-23. (Las citas del presente ensayo se refieren por lo general a las primeras ediciones con las cuales se han integrado estas Obras Completas .)

${ }^{4}$ Publicado un año después, con prólogo de Silvio Frondizi, Buenos Aires, De Palma, 1945 y reeditado en México, con prólogo de Horacio Labastida, México, UNAM/Miguel Ángel Porrúa, 1988 (Biblioteca Mexicana de Escritores Politicos).

5 Jesús Reyes Heroles, "Discurso pronunciado en el pleno de trabajo efectuado en Hermosillo, Sonora", desús Reyes Heroles, Discursos Politicos, 1972-1975. México, Partido Revolucionario Institucional, 1990, p. 28. 
Apenas concluidos sus estudios, se inició en la docencia como profesor adjunto del Seminario de Derecho del Trabajo en la propia UNAM: luego, y hasta 1963, como maestro de Teoría General del Estado.

Los caminos

Su formación académica continuó durante 1945 en las universidades de Buenos Aires y La Plata, asi como en el Colegio Libre de Estudios Superiores de Buenos Aires. Comenzó entonces una sólida y permanente relación con intelectuales latinoamericanos ocupados en la búsqueda de nuevas formas de contribuir al desarrollo de nuestros pueblos.

Al volver a México, en 1948, se desempeñó como profesor de economía en la Escuela Superior de Comercio y Administración del Instituto Politécnico Nacional. Ese mismo año inició una larga y fecunda, aunque en ocasiones atropellada, carrera en la administración pública, porque su temperamento lo inclinó como crítico, como contestatario, a renunciar a la comodidad y los privilegios que le brindaba el poder politico, en defensa de sus convicciones intelectuales, y su incuestionable defensa de la libertad,

como condición para la actividad plena del hombre es requisito de todo aquello en que creemos. Sin ella las ideologías se convierten en dogmas; la ciencia en secta de pocos: la técnica en instrumento sin finalidad; la política en negociación minúscula o acomodo estrecho; el arte se esteriliza y es simple mecánica; la moral se encanija; el nacionalismo resulta privilegio exclusivo de los fuertes; las divergencias se transforman en discordias; la convivencia en conformista sumisión. Porque sin ella no hay verdaderos compromisos, ni auténticos acuerdos. Porque sin la libertad, el trabajo, de medio de realización del hombre, se convierte en instrumento enajenante, y el hombre, de ser que piensa y actúa, pasa a ser entidad que obedece, a guarismo inerte. Cuando no hay libertad, la conciencia se disuelve, porque sin la libertad hasta el derecho a equivocarse se pierde y la supuesta infalibilidad se impone. Únicamente quien es libre puede equivocarse, pero únicamente quien es libre reconoce la equivocación y puede rectificar para seguir adelante. La vida misma es inconcebible sin la libertad, pues únicamente vive lo que es libre. ${ }^{6}$ 
Fue asesor de la Secretaria del Trabajo: luego presidente sustituto del Grupo Especial número 1 de la Junta Federal de Conciliación y Arbitraje: seria también representante mexicano a una serie de conferencias latinoamericanas, como la Conferencia Latinoamericana de la Organización Internacional del Comercio y el Empleo. llevada a cabo en La Habana. Cuba, en 1947, donde colaboró en la redacción de La Carta de La Habana: ${ }^{12}$ en el Consejo Interamericano de Comercio y Producción. Chicago, EUA, 1948; el Consejo Interamericano de Comercio y Producción. Santos. Brasil. 1951: la Sexta Conferencia Interamericana de Seguridad Social, México. 1960, y la Segunda Conferencia Interparlamentaria Americana. Santiago de Chile, 1961 .

Asumió la Secretaría General del Instituto Mexicano del Libro en 1949, en donde permaneció hasta 1953. En forma paralela trabajó en el Instituto de Estudios Politicos y Sociales del PRI, durante la campana como candidato presidencial de su paisano. Adolfo Ruiz Cortines. Pasadas las elecciones ocuparia la Jefatura de Estudios Económicos de Ferrocarriles Nacionales de México hasta 1958. cuando fue nombrado Subdirector General Técnico del Instituto Mexicano del Seguro Social.

Fue diputado federal en la XLV Legislatura Federal, de 1961 a 1964. periodo en el que también se le designó Director General de Petróleos Mexicanos. ${ }^{8}$ y como tal, asumió la presidencia del VII Congreso Mundial del Petróleo realizada en México.

Su paso por la paraestatal, durante el sexenio del presidente Gustavo Díaz Ordaz, sentó las bases para la transformación de la empresa y para la redefinición de las relaciones entre los trabajadores y los administradores. Asimismo se pronunció por la honestidad, el orden, la disciplina y la eficiencia en Petróleos Mexicanos. Sus metas fueron ambiciosas y, como él mismo lo advirtiera. estaba "inconforme de buena fe". Al final de su gestión se registró el incremento en reservas probadas: hubo un auge de la

suscripción de la Constitución Federal de 1824, en el 'Año de la República Federal y el Senado'", Discursos Politicos..., op. cit., pp. 508-509.

7 Jesús Reyes Heroles, La Carta de La Habana (comentarios y digresiones), México, EDIAPSA, 1949 (Colección de Temas Económicos y Politicos Contemporáneos de México).

8 Cf. Alejandro Sobarzo Loaiza. "Jesús Reyes Heroles y su paso por Petróleos Mexicanos", desús Reyes Heroles y el petróleo. México. Asociación de Estudios Históricos y Politicos Jesús Reyes Heroles. A.C.. 1992 (Cuadernos 4). 
petroquímica y se dio gran importancia a la investigación petrolera al crear, el 23 de agosto de 1965, el Instituto Mexicano del Petróleo. como organismo descentralizado con carácter preponderantemente técnico, educativo y cultural.

Sin duda la tenacidad del abogado que gravitaba en Reyes Heroles, del nacionalista a ultranza, coadyuvaron a que, luego de una década de celebrar con empresas petroleras los contratos-riesgo, se lograra la prescripción de concesiones o contratos otorgados -en términos que contradijesen la Ley Reglamentaria del Artículo 27 Constitucional en el Ramo del Petróleo- que en 1958 había dictaminado el impedimento de conceder remuneración por servicios en forma de porcentajes en productos, ni participación en los resultados de las explotaciones.

\section{El desafio}

En 1970 fue nombrado Director del Combinado Industrial de Ciudad Sahagún (Diesel Nacional. Siderúrgica Nacional y Concarril) y. escasos dos años más tarde. llegaria a la Presidencia del Comité Ejecutivo Nacional del Partido Revolucionario Institucional ${ }^{9}$ para. desde ese instituto político, convertirse en el ideólogo nacional, que asumió la tarea esencial de.

desmantelar las fortalezas ideológicas de aquellos que se oponen al proceso revolucionario: vencer esas resistencias, no por intangibles menos fuertes; precisar y llevar a sus últimas consecuencias la concepción que nos guía y difundirla. de manera que se convierta cada vez más en el pensamiento común de los mexicanos; ir, en síntesis, a una activa y constante lucha cultural, que supere las resistencias activas $o$ pasivas [...] somos partidarios de reformas revolucionarias. no reformistas: reformas rápidas y profundas, pero armonizadas entre si y con el todo social, de modo que su adopción no resulte contraproducente al objetivo de justicia social y libertad personal que perseguimos [...] Vamos a hacer pólitica [...] Hagamos, pues, política en todas partes [...] politica en todas partes y a todas horas. ${ }^{10}$

${ }^{9} \mathrm{Cf}$. Rodolfo Echeverría Ruiz, "Contar cabezas, no cortarlas". Jesús Reyes Heroles y la politica partidista, México. Asociación de Estudios Históricos y Politicos Jesús Reyes Heroles, A.C., 1992 (Cuadernos 3).

10 "Discurso pronunciado en la toma de posesión como Presidente del Comité Ejecuti- 
Hacer política demandaba pasión, pero con mesura, sosiego interno, dominio de sí mismo, y no de los otros. Hacer política era sinónimo de lograr el acuerdo fundamental, entendido como sustento del ejercicio democrático, y a escala nacional, era el terreno que permitia la identificación de todos los mexicanos: las reglas y normas que le daban coherencia a la nación entera.

La defensa tenaz de la libertad de conciencia, tan bien aprendida de los hombres de la Reforma, lo llevaba a insistir en que.

formamos un partido, no una iglesia, y menos una secta. Por consiguiente, no existe en nuestra organización rigidez dogmática. Esto permite, dentro de la coincidencia de todos los miembros de nuestro partido en las ideas centrales en torno a las cuales nos agrupamos. matices ideológicos, diferencias que, sin afectar la línea medular, facilitan, por la libre discusión, el enriquecimiento del ideario que nos aglutina. Porque coincidimos en lo principal, podemos discutir en lo accesorio."

El hombre que preconizaba que la forma es el fondo, el que insistía en contar cabezas, no cortarlas, el que pugnaba por la disciplina interna pudo -en menos de tres años, de febrero de 1972 a agosto de 1975- delinear y orientar los nuevos rumbos, el nuevo sentido de la lucha partidista que, decía, debía ser contra

aquellos realistas que, a nombre del realismo, condenan las ideas y los ideales. Luchemos contra aquellos que, por preservar la pureza de los principios, ignoran la eficacia de la acción. Luchemos contra los que, a nombre del orden, quieren la dictadura para oprimir, eso sí, igualitariamente a todos. Luchemos contra quienes, a nombre de la libertad. quieren el desorden. ${ }^{12}$

Después de su gestión como Director General del Instituto Mexicano del Seguro Social ${ }^{13}$ durante el bienio 1975-1976, fue nombra-

vo Nacional del Partido Revolucionario Institucional", Jesús Reyes Heroles, Discursos Políticos..., op.cit.. pp. 14, 21. 23.

11 "Estado. programa y partido". Historia documental del Partido de la Revolución, 1963-1968. México, PRI/CAP, 1982, t. 8, p. 64.

12 "Discurso pronunciado en la Convención Estatal Ordinaria celebrada en la ciudad de San Luis Potosí. S.L.P.", Discursos Politicos..., op. cit., pp. 176-177.

${ }^{13} \mathrm{Cf}$. Fernando Zertuche Muñoz, Jesus Reyes Heroles y lit seguridad social. México, 
do Secretario de Gobernación, ${ }^{14}$ de 1976 a 1979, periodo en el cual se convirtió en el gran promotor de la Reforma Politica que, como insistiera, no iba contra nadie ni nada, sino en favor de México. Un propósito que se perfilaba como el medio para hacer más sólida y fecunda la estabilidad politica, sobre la base de que estabilidad política no significa sociedad en descanso, sino en movimiento, con impetu transformador.

Se trataba de que,

en un país de mayorias constantes las minorias tengan en la vida politica el peso que como tales les corresponde [...] Si la democracia es el gobierno del pueblo por el pueblo, en nuestra práctica la democracia podia consistir en el gobierno de todo el pueblo exclusivamente por su mayoría. Teniamos que encontrar un sistema en que, sin caer en la democracia disolvente, las minorías, expresando sus puntos de vista, pudieran ser consideradas en su justa dimensión numérica. ${ }^{15}$

Jesús Reyes Heroles ocupó su último cargo político adminsjtrativo en 1982, cuando el presidente Miguel de la Madrid lo designó Secretario de Educación Pública, ${ }^{16}$ función que desempeñó hasta su muerte.

Siendo titular del ramo recuperó el sentido de la educación como motor del progreso hacia una sociedad racional moderna; como proceso de socialización; como sinónimo del desarrollo formativo que nos permite asumir como propios los valores que la nación ha escogido para sí. Fue entonces cuando postuló la revolución educativa, que reconocia como tarea urgente descentralizar los servicios.

Como en tantas otras etapas de su vida, Reyes Heroles de nuevo torna sus reflexiones a la historia nacional, buscando, en las raices las razones para una defensa pertinaz del laicismo en la educación.

Asociación de Estudios Históricos y Políticos Jesús Reyes Heroles, A.C., 1992 (Cuadernos 2).

${ }^{14}$ Cf. Rodolfo Duarte Rivas, Jesús Reyes Heroles y la reforma política, México, Asociación de Estudios Históricos y Políticos Jesús Reyes Heroles, A.C., 1994 (Cuadernos 7).

15 "Discurso pronunciado a nombre de los Tres Poderes de la Unión, en el aniversario de la Promulgación de la Constitución de 1917". Avanzamos en la democracia, perfeccionándola, o retrocedemos, México. Ediciones del Centro de Documentación Política. A.C., 1978, p. 15.

${ }^{i 6}$ Cf. Luis Villoro. "Educación e historia", Jesús Reyes Heroles y la educación. México. Asociación de Estudios Históricos y Politicos Jesús Reyes Heroles. A.C., 1994 (Cuadernos 5). 
logro fundamental de la Reforma, como garante de libertad. Una vez más su actuar seria congruente con su pensar. El hombre que dedicara significativos esfuerzos a una permanente apologia de la generación de la Reforma -que había triunfado en su lucha por lograr la separación de la Iglesia y el Estado- recordaba claramente las lecciones de la historia pasada. ${ }^{17}$

La cosecha

Reyes Heroles, intelectual y conscientemente, identificaba a la politica como actividad cultural:

Por el verbo, por la reflexión y por la decisión, el político del más alto rango procura moldear, valiéndose de ella hasta donde es posible, una realidad rebelde, nada plástica, de conformidad con las ideas en que cree. La cultura tiene un claro sentido politico, pues, en cuanto no se entiende como yuxtaposición o hacinamiento de conocimientos, supone la búsqueda de perfeccionamiento, empezando por el propio y, por lo tanto, implica perenne transformación, y constante renovación, e impele a estar dentro de la sociedad en que se vive en una posición critica, con el deseo de cambiarla o conservarla. Cualquier obra cultural, por individual que sea, por mucho que agote una individualidad, la trasciende, adquiere sentido objetivo cuando los demás la aprecian. consumen o rechazan. ${ }^{18}$

Asi, desde la década de los cuarenta, Reyes Heroles se abocó ininterrumpidamente al estudio y la reflexión. De ahi surgió un compromiso permanente de análisis sobre el pensamiento universal y los representantes de la ideologia mexicana decimonónica, constructora del Estado nacional. Teóricos como Maquiavelo, Locke y Hobbes, Montesquieu y Rousseau: Burke, Nietzche, Ortega y Gasset, Croce y Gramsci ocupan por igual su atención y determinan sus pasos como investigador, al tiempo que va escudriñando en la

${ }^{17}$ Cf. Eugenia Meyer, Jesús Reyes Heroles, La Iglesia y el Estado. México. Asociación de Estudios Históricos y Políticos. Jesús Reyes Heroles. A. C., 1995 (Cuadernos 8).

18 Jesús Reyes Heroles, "La historia y la acción". Discurso pronunciado con motivo de su recepción como académico de número en la Academia Mexicana de la Historia. correspondiente de la Real de Madrid, el 7 de septiembre de 1968, apud La Historia y la Acción. La Revolución y el desarrollo político de México, Madrid. España. Seminarios y Ediciones, S.A., 1972, p. 172 (Hora H). 
historia de México, preparándose para su encuentro y su diálogo con los intelectuales que forjaron nuestro liberalismo: Otero, Rejón. Mora, Prieto, Juárez, Arriaga, Zarco, Ramírez, Ocampo. Justificaba este encuentro afortunado reconociendo que habia llegado

al siglo XIX mexicano, comprobando la unicidad de la historia, de adelante hacia atrás o de atrás hacia adelante, en un perpetuo remontarse o aventurarse. El periodo, una vez iniciado su estudio, tuvo otro singular atractivo $[. .$.$] tratar con hombres que hacian la historia y también la escribian. { }^{19}$

Gradualmente fue comprendiendo que la politica contemporánea está sustentada en una continuidad de ideas e instituciones, más que en rupturas. Encontró asi las raices del pensamiento actual mexicano en las influencias españolas y novohispanas, tanto como en los teólogos y los humanistas de los siglos XVI y XVIII respectivamente.

Fue entonces que Reyes Heroles descubre su tema como historiador y también su profunda afinidad como politico en el liberalismo mexicano. ${ }^{20}$ Vena de identidad y de continuidad; hilo conductor de los tres grandes movimientos de nuestra historia: la Independencia, la Reforma y la Revolución. Decia en 1957, en la introducción a su obra magna:

Abordar el estudio del liberalismo en nuestros días significa, más que acercarse a una pura elaboración doctrinal, examinar una rica experiencia histórica. El liberalismo surge de la razón y se traduce en actividad [...] Viniendo de la razón, el liberalismo no se queda en ella. Al nacer como moral -las relaciones del hombre con el hombre se explican y se fundan en la ética - el liberalismo encontró en sí mismo los incentivos para la realidad [...] El liberalismo - discutidor y todo- fue actividad y lucha por transformar la realidad [...] La experiencia liberal mexicana es una de las más aleccionadoras. En México. peldaño a peldaño, la idea liberal en acción fue obteniendo realidades y, siendo permeable a éstas. fue adquiriendo matices de originalidad. Por ello el proceso del liberalismo mexicano fue sumamente complejo y resulta difícil seguir sus huellas, a veces imperceptibles. Localizadas nos conducen a un liberalismo dotado de originalidad. ${ }^{21}$

\section{Ibidem, p. 147}

${ }^{20} \mathrm{Cf}$. Jorge Sayeg Helú, Jesús Reyes Heroles y el liberalismo mexicano. México. Asociación de Estudios Históricos y Politicos Jesús Reyes Heroles, A.C.. 1994 (Cuadernos 6).

21 Cf. Jesús Reyes Heroles. El liberalismo mexicano I. Los origenes, México. UNAM. Facultad de Derecho, 1957, p. IX. 
En esa búsqueda de rastros, Reyes Heroles consigue integrar las ideas que dieron vida al liberalismo mexicano que, como bien asegura, a diferencia del francés o del inglés o del estadunidense, es eminentemente social en su propósito por limitar los grandes abusos en el derecho a la propiedad, y así contribuir al desarrollo de las llamadas clases indigentes.

Buscando una lógica en la evolución de la inteligencia mexicana, Reyes Heroles estructura su Liberalismo mexicano en tres partes, a saber: los origenes, la integración de las ideas y la sociedad fluctuante. A él corresponde el mérito de haber advertido el vínculo y la continuidad entre el liberalismo social y la Revolución, cuyas raices y legitimidad ideológica, concretadas en la nueva Carta Magna de 1917, retoman la tradición original de nuestro liberalismo.

Ya en 1960, al conmemorarse el medio siglo de la gesta revolucionaria, concluía que los constituyentes de Querétaro habian entendido el alcance y significado de encarar con audacia e imaginación el problema económico y social del siglo XX y,

por eso, el texto que nos legaron fue preponderantemente social, dando normas para que el Estado pueda afirmar su supremacia frente a nuevas fuerzas, fundamentalmente económicas y previendo, simultáneamente, que no resurjan las viejas fuerzas que mantuvieron fluctuante durante largo tiempo a la sociedad mexicana. ${ }^{22}$

Su lealtad a los caminos trazados por los hombres del siglo pasado sería permanente; da fe su incesante e ininterrumpida tarea por descubrir y entender ese mundo decimonónico, e incluso por desentrañar lo que entendió por "involuciones históricas", que brillantemente ejemplifica, con José María Gutiérrez de Estrada. ${ }^{23}$

22 "La Iglesia y el Estado", México, Cincuenta arios de Revolución. México. Fondo de Cultura Económica, 1961, t. III, p. 372.

23 Cf., "José María Gutiérrez de Estrada gobernante", Sabado, Suplemento del Unomásuno. México, 11 de julio de 1981, núm. 192, y los inéditos que seguramente serian parte de un texto mayor que quedó inconcluso: "Notas sobre Gutiérrez de Estrada: el contexto del proyecto monárquico, 1840". "Gutiérrez de Estrada: 1840. El proyecto monárquico" y "Gutiérrez de Estrada: la reacción, 1840-1841". (Todos aparecerán en la parte histórica de las Obras Completas). 
El destino

La doble condición de intelectual y politico lo llevó a reflexiones múltiples y a la formulacion de principios. Es asi como se identificó con el pensamiento de quienes no conciben la vida intelectual como distinta, o al menos reñida con las tareas del Estado, sino, por el contrario, integran ambas.

La oportunidad de asumir la posición y el compromiso pleno llegó en 1968, al ingresar a la Academia Mexicana de la Historia, en donde con lucidez singular trazó los limites y las convergencias entre el historiador y el político que en su persona se entrecruzaban y reconocian. ${ }^{24}$

Reyes Heroles afirmaba que había llegado a la historia, por vocación o equivocación, buscando explicaciones al mundo en que vivia y que lo obligó a interrogarse: “¿Podia la Revolución en que naci y me desarrollé ser producto de generación espontánea?" 25 Y, si en efecto, "todos los caminos conducen a la historia y la historia está en las entrañas de todo conocer o hacer", consecuentemente las relaciones de los protagonistas, las ideas y los fines de los que fueron haciendo los caminos del derecho, la sociologia, la ciencia, la literatura, la economia, la politica en su muy amplio sentido, el arte, la milicia, la teologia suman en su conjunto la esencia de la historiografía, entendida ésta como la cumbre del conocimiento, o sea, la historia de la historia.

Diversos caminos se convierten en medios para alcanzar el propósito último de la realización histórica que demanda establecer el vínculo entre el conocimiento y los hechos; entre la teoría y la práctica, ya que la historia pertenece al conocer, "aun cuando en mucho se ocupe de describir el hacer e influya sobre éste."

Ciencia y experiencia, teoria y praxis, saber y hacer, son categorias todas que permiten la vinculación en la teoría política. Por ello Reyes Heroles detectó -en el pensamiento de Aristóteles primero, como padre de dicha teoría, y luego con Maquiavelo, el gran observador - la necesidad de seleccionar y de depurar, la experiencia humana, la práctica especifica de los gobernantes, para poder así construir las recomendaciones a éstos.

${ }^{24}$ Reconocimientos como su ingreso a la Real Academia de la Historia de España, en 1969. y el título de doctor Honoris Causa de la Universidad de Alcalá de Henares en 1981. reafirmarian su prestigio académico y su doble faceta de intelectual y político.

${ }^{25}$ Cf. "La historia y la acción". La Historia y la Acción.... op. cit, pp. 146 y ss. 
Ciertamente, como pensador, como historiador, entendia a la política como forma de acción, que si bien no es la única, si condensa y resume la parte de ella que lleva a la toma de decisiones que. lejos de surgir del vacío, se apoyan en el todo, quizá sin comprender la totalidad de cada uno de sus componentes.

La razón de Estado, debe mantener una dialéctica incesante con la contrarrazón, a fin de permear una serie de principios que se significan como disposición permanente, en la búsqueda de experiencias e ideales; de formas para la acción, para así conciliar la teoria que se profesa.

Íntima relación entre las ideas y las acciones que decantan en el hacer de la historia, entendida como la búsqueda del

sentido de los hechos, explicarlos hasta donde es posible y situarse en posición equidistante entre aquellos que todo lo ven como fruto de la necesidad y aquellos que todo lo atribuyen a la voluntad del hombre, admitiendo para éste que, de grado o por fuerza, está en aptitud de escoger en las máximas alternativas. Escribir historia impone formar parte del presente, tratando hechos que pertenecen al pasado, sabiendo que la historia es un "proceso continuo de interacción entre el historiador y sus hechos, un dialogo sin fin entre el presente y el pasado" diálogo no entre individuos aislados de hoy y de ayer, sino "entre la sociedad de hoy y la sociedad de ayer". 26

Reyes Heroles trata de identificarse entonces con los historiadores que se dejan ver en sus obras, tal vez no como protagonistas, pero sí como elementos activos, porque de otra suerte la historia se torna imposible, hasta aburrida y muere. En consecuencia, se ve precisado a reconocer el demonio de la subjetividad, que aparece desde la elección temática, la elaboración de la hipótesis de trabajo, la construcción heuristica y consecuentemente la resultante hermenéutica.

Conocedor de las sustentaciones teóricas del historicismo, del positivismo y del materialismo histórico, se las ingenia para abrevar de todas, sin comprometerse irracionalmente con ninguna: se niega por tanto a asumir dogmas y sofismas. Insiste en la irrepetibilidad de los hechos históricos, en marcar los valores y las diferencias entre la historia hecha y la historia por hacer.

26 "La historia y la acción", op. cit. El entrecomillado corresponde a citas de Edward H. Carr, ¿Qué es la Historia?. Barcelona. Editorial Seix Barral, S. A. 1987, pp. 40 y 73. 
De Gramsci toma en préstamo recursos para concluir que:

Historia y política están estrechamente unidas, o mejor, son la misma cosa, pero es preciso distinguir en la consideración de los hechos históricos y de los hechos y actos políticos. En la historia, dada su amplia perspectiva hacia el pasado y dado que los resultados mismos de las iniciativas son un documento de la vitalidad histórica, se cometen menos errores que en la apreciación de los hechos y actos políticos en curso. El gran politico debe, por ello, ser "cultísimo", es decir, debe "conocer" el máximo de elementos de la vida actual, conocerlos no en forma "libresca", como "erudición", sino de una manera "viviente", como sustancia concreta de "intuición" política. ${ }^{27}$

Reyes Heroles, el historiador, advierte que la historia no desempeña en todas las sociedades el mismo papel, toda vez que, si está constituida por los muertos que hablan a través de los vivos, hay pueblos abrumados por la historia, que llevan sobre sus espaldas la servidumbre del ayer, sujetos a las glorias que desaparecieron, mismas que se sobrevaloran en el presente en función del pasado. impidiéndoles, en ocasiones - muy a la manera de Croce-, alcanzar la hazaña de la libertad.28

Asimismo se manifiesta por condenar a los pueblos aquejados de amnesia histórica, que por falta de comunicación con un pasado grandioso o por falta de aprecio y conocimiento del pasado con que cuentan, se convierten en pueblos sin futuro. Y, para el caso de México, reconoce una vitalidad histórica que radica en la constante revisión que de sí mismo puede hacer, en la sabiduría histórica que induce a sacar fuerzas de la debilidad, que aconseja negociar en vez de pelear,

es la sabiduría histórica de un pueblo que hizo una Revolución que nunca intentó rebasar sus fronteras y que defendió éstas precisamente para afirmar el derecho a buscar su propio camino. Es la sabiduría de un pueblo que no es adorador del triunfo. Como pueblo viejo y joven que somos, el pasado, que ayudó al presente, hace que éste, que pronto será pasado, contenga en sí los gérmenes del futuro. ${ }^{29}$

${ }^{27}$ Apud Jesús Reyes Heroles, "La historia y la acción". La Historia ... op. cit. p. 157.

${ }^{28} \mathrm{Cf}$. Benedetto Croce, La historia como hazaña de la libertad. México. Fondo de Cultura Económica. 1960 (Colección Popular núm. 18).

29 "La historia y la acción". La Historia..., op. cit.. pp. 162-163. 
Reyes Heroles encuentra en páginas de la centuria pasada la definición de intelectual político, con la cual puede explicar a los otros cómo se concibe a si mismo, consciente como estaba de los reproches generalizados, que se heredan para ser retomados por los intelectuales, quienes irracionalmente condenan la actividad política de los de su gremio. Se rebela entonces y afirma que, la actuación requiere del pensamiento y que el pensamiento se amplía con la actuación ligera o profunda, pequeña o grande; que, en fin, pensar y actuar se robustecen al comunicarse. El político recalca la propensión del intelectual a erigirse en severo juez en algunos casos, sin pasar por la prueba de la acción, en otros casos para resarcirse de la frustración en el actuar.

$\mathrm{Si}$, como decía Ranke, el historiador debe hacerse viejo, para Reyes Heroles, la historia hecha y la historia por hacer constituyen tarea vital y, en consecuencia,

hacer historia exige años y ayuda a tenerlos. La historia, que ayuda a la longevidad, parece ser que la demanda. Los años dotan de altura para el juicio histórico; obligan a poner entre interrogaciones lo que se aseguraba; otorgan capacidad de duda e imponen, a veces, el recurrir a los puntos suspensivos. ${ }^{30}$

Y esa irreverente y demandante exigencia de la historia, la de los muchos años -que quizá permitan a los más viejos, más sabios. salir de dudas y lograr suprimir o reemplazar los puntos suspensivos-, no le fue dada a Jesús Reyes Heroles. El extraño destino, que describiera Monsiváis. "de un hombre profundamente inteligente, obsesionado con la importancia de las ideas en la vida de la República, que de hecho careció de interlocutores políticos y que fue muy oído y escasamente entendido, que fue muy admirado y apenas analizado", ${ }^{31}$ se ve truncado el 18 de marzo de 1985 , cortando de tajo, a sus 64 años, una vida de extraordinaria y fecunda capacidad intelectual y política.

EUGENIA MEYER

30 "La historia y la acción", La Historia..., op. cit., pp. 173-174.

31 Carlos Monsiváis, "Notas sobre el ideólogo y el político. Reyes Heroles, muy oido y poco entendido: admirado y apenas analizado". México. Proceso, Semanario de Información y Análisis, 25 de marzo de 1985, núm. 438, p. 8. 